\title{
Nutritional status and morbidity pattern of government primary school children in north Kolkata of West Bengal, India
}

\author{
Palash Das ${ }^{1}$, Mausumi Basu², Gautam Dhar ${ }^{3}$, Sarmila Mallik ${ }^{4}$, Ranabir Pal $^{5}$
}

'Associate Professor, Department of Community Medicine, Midnapore Medical College, Paschim Medinipur, West Bengal, India. ${ }^{2}$ Assiociate Professor, Department of Community Medicine, IPGME\&R, Kolkata, India. ${ }^{3}$ ADME, Swasthya Bhavan, Kolkata, West Bengal, India. ${ }^{4}$ Associate Professor, Department of Community Medicine Calcutta National Medical College, Kolkata, India. ${ }^{5}$ Professor, Department of Community Medicine, All India Institute of Medical Sciences, Jodhpur, Rajasthan, India.

\begin{abstract}
The nutritional status of children adversely affects their physical and mental growth. This study examined the nutritional status and morbidity pattern of government primary school children in north Kolkata of West Bengal, India. A crosssectional study was conducted among 10 primary schools using interview techniques and anthropometric and clinical examinations. Of the 502 children, $40.2 \%$ children showed poor hygiene. The upper class students showed significantly poorer hygiene than that of lower class students. Anemia rate was $22.3 \%$ in these children and class II and III students showed significantly more anemia. Dental caries were found among $29.9 \%$ children and class II and III students showed significantly higher rate. About $10.4 \%$ children were found with enlarged tonsils and class I and III students showed higher prevalence. A major group of children (39.4\%) gave the history of worm expulsion and the infestations of worms were observed significantly higher among lower class students. Vitamin B-complex deficit was observed among $20.7 \%$ and the deficiency was markedly observed among class II and IV students. Under-weight children were found in one-third of study population. There was no significant difference in nutrition among the participants from the various classes. There was no case of severe under-nutrition or stunting and wasting found in this study population. The findings of various nutritional status and morbidity patterns in this study highlight the needs to undertake various initiatives in relation to health promotion and prevention in primary schools.
\end{abstract}

Keywords: Morbidity pattern, Nutritional status, Primary school students, North Kolkata.

\section{Introduction}

Children morbidity is a major public health concern as this adversely affects their physical and mental growth. Poor health and malnutrition may impair both the growth and cognitive development of primary school children. There is growing evidence of considerable burden of morbidity and mortality due to infectious diseases and malnutrition in school children. Studies in different countries identified the following in primary school children: respiratory problems, diarrheal disease, nutritional disorders, anemia, parasitic infestations, pediculosis, caries teeth, refractive errors, skin diseases, ear and throat problems, tic disorders, sleeping disorders etc. ${ }^{1-13}$ Prevalence of smoking was also found among primary school children. ${ }^{12}$ Factors affecting food choice, lifestyle behavior and psychological well-being are also important issue in children of primary school. ${ }^{7,8,11}$ Health and illness concept, classroom climate, poor environmental status, family income, nutrition education and mental health were studied in different parts of the world for health

\section{Practice points}

- Poor health and malnutrition may impair both growth and cognitive development of primary school children.

- The present study showed various signs of deficiencies and ill health among primary school children.

- Hygiene level was found to be poor in a large proportion of school children.

- Most common causes of morbidity were anemia, vitamin deficiency, enlarged tonsils, and caries teeth.

- Most of these morbidities can be tackled with emphasis on health education and health promotion at school level.

and nutrition among primary school children. A family

Correspondence: Dr. Palash Das, Associate Professor, Department of Community Medicine, Midnapore Medical College, Paschim Medinipur, West Bengal, India. Email:palashdasdr@gmail.com. 
environment and health education play a positive role in students' good health and nutrition. ${ }^{1,6,11,12}$ The prevalence of sore throat, evening cough, cough for more than 3 months, morning phlegm and wheezing were found to be significantly higher among children. ${ }^{1,14}$ Adequate drinking and washing water supply and ventilated improved pit latrine are intended to reduce widespread infectious diseases among primary school students. ${ }^{2}$ In north Kolkata, there is limited data on nutritional status and morbidity pattern among primary school children. This study examined the nutritional status and morbidity pattern of government primary school children in north Kolkata of West Bengal, India.

\section{Methods}

A cross-sectional study was conducted in north Dum-Dum municipality of Kolkata, West Bengal of India among primary school children of grade I to grade IV of selected government schools from January to April 2011. The schools were selected by simple random sampling and all the students of 10 schools were included in the study. The purpose of the study was fully explained to the school principals and written consents were taken from them to carry out the study. The district health officers of North 24Parganas were informed about the study. The municipal authority was also taken in confidence for the work.

All the primary school children from grade I to grade IV who were present were enumerated on the pre-assigned days. For the absentees, three extra visits were done to locate them in the school for examination. If sickness was the reason for not attending school, it was recorded as per information to the schools with the medical certificate. For the data collection, a semi-structured interview technique was developed and presented before public health specialist and modified accordingly. The pre-testing was done at a near-by school among 40 students; 10 students from each (I to IV) grade and further changes were made. The interview technique included the demographic information, anthropometric data, personal hygiene and morbidity patterns. Interviews of students were followed by anthropometric measures and clinical examinations. Each child was identified by name, age, sex and religion. Date of birth was obtained from the school records in order to ensure the data quality. History of worm expulsion within last 15 days was considered as worm infestation. A brief health education session was organized for the class teachers and students after completion of the study to increase awareness of health promotion. Each student received a single dose of Albendazole $(400 \mathrm{mg})$ orally as de-worming measure.

A flat spring balance was used to measure the weights (in kilogram) of students and height in centimeter was measured with the help of measuring tape. A thorough general and systemic health examination including a clinical history was done for each child. The personal hygiene of students was assessed and recorded. Eye examination was done by an optometrist by reading of Snellen's chart and other standard techniques. Dental examination was done in adequate daylight. ENT check-up was done with the help of a torch. Significant limitations in two areas of adaptive behavior (communication and social skills) were used to diagnose a case of mental retardation. ${ }^{15}$ If diseases were found then appropriate advice was given with prescribing medication. The parents were invited to collect background data (education, occupation and monthly income) and given information about their children's health condition and if needed suggested to contact the nearest health center.

Protein energy malnutrition was assessed using anthropometric parameters in terms of weight for age, height for age and weight for height and assessed undernutrition (low weight for age), stunting (low height for age) and wasting (low weight for height) according to Waterlow classification ${ }^{15}$ and Indian Academy of Paediatrics. ${ }^{16}$ Head to heel examination was done to detect vitamin and mineral deficiency.

Data were entered in the Microsoft excel and analysis was done with the help of tabulation compilation and test of significance ( $p$-value, chi square test).

\section{Results}

The total number of primary school children in ten selected schools was 530 and among them 502 (94.7\%) were interviewed and examined. The number of boys was 254 $(50.6 \%)$ and girls were 248 (49.4\%). Majority (89.2\%) of students belonged to lower middle socio-economic class according to Modified Kuppuswamy Classification. The range of age of the participants was between 5 to 9 years. Poor hygiene (presence of dirt under nails, pediculosis scalp, and unclean skin) was found at the rate of $40.2 \%$ of children. Upper class students (III, IV) showed significantly poorer hygiene than that of lower class students (I, II) of primary schools $\left(\chi^{2}=19.95, \mathrm{df}=3, \mathrm{p}<0.001\right)($ Table 1$)$.

Table 1: Distribution of primary school children according to class and hygiene level

\begin{tabular}{|c|c|c|c|}
\hline Class & \multicolumn{2}{|c|}{ Hygiene level } & \\
\hline & Poor (\%) & Good (\%) & Total \\
\hline I & $34(27.42 \%)$ & $90(72.58 \%)$ & 124 \\
\hline II & $30(32.61 \%)$ & $62(67.39 \%)$ & 92 \\
\hline III & $56(44.44 \%)$ & $70(55.56 \%)$ & 126 \\
\hline IV & $82(51.25 \%)$ & $78(48.75 \%)$ & 160 \\
\hline Total & $202(40.23 \%)$ & $300(49.76 \%)$ & 502 \\
\hline
\end{tabular}

$\chi^{2}=19.95, \mathrm{df}=3, \mathrm{p}<0.001$

Anemia was detected among $22.3 \%$ of these children and middle group of primary school students showed significantly high prevalence $\left(\chi^{2}=9.82, \mathrm{df}=3, \mathrm{p}<0.05\right)$ (Table 2). The infestation of intestinal worms were observed in $39.4 \%$ children which was significantly higher among lower class students $\left(\chi^{2}=16.08, \mathrm{df}=3, \mathrm{p}<0.01\right)$. 
Das et al. - Nutritional status and morbidity pattern of primary school children

Table 2: Distribution of students according to the presence or absence of clinical features

\begin{tabular}{|c|c|c|c|c|c|c|}
\hline Character & Present /Absent & Class I & Class II & Class III & Class IV & Statistical values \\
\hline \multirow{2}{*}{ Anemia } & Present & $26(20.9 \%)$ & $26(28.2 \%)$ & $36(28.5 \%)$ & $24(15 \%)$ & \multirow{2}{*}{$\begin{array}{c}\chi^{2}=9.82 \\
\mathrm{p}<0.05\end{array}$} \\
\hline & Absent & $98(79 \%)$ & $66(71.7 \%)$ & $90(71.4 \%)$ & $136(85 \%)$ & \\
\hline \multirow{2}{*}{ Worms Infestation } & Present & $64(51.6 \%)$ & $40(43.5 \%)$ & $48(38.1 \%)$ & $46(28.8 \%)$ & \multirow{2}{*}{$\begin{array}{c}\chi^{2}=16.08 \\
p<0.01\end{array}$} \\
\hline & Absent & $60(48.4 \%)$ & $52(56.5 \%)$ & $78(61.9 \%)$ & $114(71.3 \%)$ & \\
\hline \multirow{2}{*}{$\begin{array}{l}\text { Signs of Vitamin } \\
\text { deficiency }\end{array}$} & Present & $18(14.52 \%)$ & $26(28.26 \%)$ & $14(11.11 \%)$ & $46(28.75 \%)$ & \multirow{2}{*}{$\begin{array}{c}\chi^{2}=20.23 \\
p<0.001\end{array}$} \\
\hline & Absent & $106(85.9 \%)$ & $66(71.7 \%)$ & $112(88.9 \%)$ & $114(71.3 \%)$ & \\
\hline \multirow{2}{*}{ Tonsils enlarged } & Present & $22(17.74 \%)$ & $6(6.52 \%)$ & $16(12.70 \%)$ & $8(5 \%)$ & \multirow{2}{*}{$\begin{array}{c}\chi^{2}=14.50 \\
p<0.01\end{array}$} \\
\hline & Absent & $102(82.3 \%)$ & $86(93.5 \%)$ & $110(87.3 \%)$ & $152(95.0 \%)$ & \\
\hline \multirow{2}{*}{ Caries teeth } & Present & $28(22.6 \%)$ & $36(39.1 \%)$ & $42(33.3 \%)$ & $44(27.5 \%)$ & \multirow{2}{*}{$\begin{array}{c}\chi^{2}=9.77 \\
p<0.05\end{array}$} \\
\hline & Absent & $96(77.4 \%)$ & $56(60.9 \%)$ & $84(66.7 \%)$ & $116(72.5 \%)$ & \\
\hline
\end{tabular}

About $20.7 \%$ of the children showed clinical manifestations of vitamin B complex deficiency and was observed significantly high among class II and Class IV students $\left(\chi^{2}=\right.$ 20.23, $\mathrm{df}=3, \mathrm{p}<0.001$ ) (Table 2). Enlarged tonsils were observed among $10.4 \%$ of children and a few students showed the inflammation of tonsils. Class I and class III students showed the higher prevalence of enlarged tonsils $\left(\chi^{2}=14.50, \mathrm{df}=3, \mathrm{p}<0.01\right)$ (Table 2). The dental caries $(29.9 \%)$ was the commonest clinical features among all health problems of the primary school children and class II and III students showed significantly higher prevalence $\left(\chi^{2}=9.77, \mathrm{df}=3, \mathrm{p}<0.05\right)($ Table 2$)$.

Average weights of the children for class I, II, III, IV were found $14.50 \pm \mathrm{SD} 3.25,18.34 \pm 4.38,18.96 \pm 3.3,21.00 \pm 3.68 \mathrm{~kg}$ respectively. Average heights of the children for class I, II, III, IV were found $104.11 \pm 7.68,112.21 \pm 9.53,115.58 \pm 8.96$, $122.45 \pm 8.38 \mathrm{~cm}$ respectively. Weights-for-age was compared with the Indian Academy of Pediatrics (IAP) classification ${ }^{16}$. There were 356 (68.9\%) students with normal weight for age and $156(31.1 \%)$ students with low weight for age. Prevalence of under-nutrition among different class of primary school children were distributed evenly. There was no significant difference among various classes $\left(\chi^{2}=1.66, \mathrm{df}=3, \mathrm{p}>0.05\right)$. There were no case of severe under-nutrition $(=$ or $<3 \mathrm{SD})$ or of stunting and wasting found in our study population (Table 3 ).

Table 3: Distribution of school children according to class and nutritional status

\begin{tabular}{|c|c|c|c|}
\hline Class & Normal & Underweight & Total \\
\hline I & $82(66 \%)$ & $42(34 \%)$ & 124 \\
\hline II & $64(69.5 \%)$ & $28(30.5 \%)$ & 92 \\
\hline III & $84(66.6 \%)$ & $42(33.4 \%)$ & 126 \\
\hline IV & $116(72.5 \%)$ & $44(27.5 \%)$ & 160 \\
\hline Total & $346(68.9 \%)$ & $156(31.10 \%)$ & 502 \\
\hline
\end{tabular}

$\chi^{2}=1.66, \mathrm{df}=3, \mathrm{p}>0.05$
Problems of eye were observed in $5.9 \%$ of children; of them almost all had refractive errors. Only $2(0.4 \%)$ cases were found with clinical iodine deficiency (goitre). Four cases $(0.8 \%)$ were found with hepatomegally. Mental retardation cases were also found in less frequency $(0.8 \%) .^{17}$ Few uncommon conditions with uneven distribution were found among these school children at the rate of $5.9 \%$.

\section{Discussion}

School health survey offered an excellent opportunity to screen a large number of primary school population with less resources. ${ }^{18}$ We identified poor hygiene, some common illnesses and nutritional deficiencies among students which highlighted the need for undertaking effective school health programs. More than $40 \%$ of children showed poor hygiene mainly in the upper class students. However, worm infestation and anemia were more prevalent in the lower class. General hygiene was found poor among our primary school students and that was similar to Jodhpur study. Lifestyle choices are formed in early adolescence; therefore, health education must begin as early as possible to influence, to adopt healthy behaviors including hygiene. ${ }^{11}$ Our study showed ever infestation of worms at the rate of $39.4 \%$, which was much lower than the findings of a study conducted by Shakya et al. ${ }^{3}$ in Nepal $(65.8 \%)$. The high prevalence of stool parasites could be related to behavioral factors such as poor hygiene, walking bare foot or lack of safe drinking water supply and open field defecation. The same Nepal study ${ }^{3}$ also found the prevalence of anemia at the rate of 58\% which was higher than this study $(22.3 \%)$, Orissa study by Chopdar et al. ${ }^{4}(25.7 \%)$ and Jammu study by Gupta et al. ${ }^{6}(11.7 \%)$. The difference in anemia prevalence may be due to the diagnostic criteria. In our study the criteria were clinical pallor for assessment of anemia whereas in the Nepal study hemoglobin estimation was done.

Dental caries were found $29.9 \%$ in our study which correspondence with Nepal study by Shakya et al. . $^{3,}$ Jodhpur 
study by Gupta et al., ${ }^{5}$ Jammu study by Gupta et $a l .{ }^{6}$ and Uganda study by Wandera et al. ${ }^{7}$ However, Chopdar et $a l^{4}$ noticed a very low prevalence of $8.5 \%$ in Orissa, India. On the contrary, higher prevalence was found in Nairobi study, ${ }^{8}$ at $50 \%$ and Yemen study, ${ }^{9}$ at $49.5 \%$. The reason of this difference was unknown; may be due to inter-observer variation at different settings.

Our study revealed $10.4 \%$ tonsillar enlargement comparable to studies conducted in Nepal ${ }^{3}$ and Turkey. ${ }^{16}$ In the present study, prevalence of refractive errors was $5.9 \%$, which was very much lower than Iranian study ${ }^{10}$ carried out by Mohammad et al., Surat study ${ }^{19}$ by Basu et al. and Kolkata study ${ }^{20}$ by Das et al. About $20.7 \%$ of school children showed the clinical manifestations of B-complex vitamin deficiencies in this study. However, very low rate $(9.3 \%)$ was observed in a study in $\mathrm{Nepal}^{3}$ and a very high rate $(42.9 \%)$ was in Orissa, India. ${ }^{4}$

Under-nutrition was observed as $31.1 \%$ in this study population which was less comparing with some other studies. ${ }^{3,21,22}$ This variability could be due to difference of environment and socio-economic conditions. There was no case of stunting and/or wasting in the present study which was contrary to other studies. ${ }^{3,21,22}$ Again among under-five children, under-nutrition, stunting and wasting all were seen in NFHS (National Family Health Survey) III in India and West Bengal. ${ }^{23}$ The overall environmental conditions of the schools were not bad with availability of latrine and urinals; but separate toilets were not found for boys and girls. Drinking water was not found in the majority of schools and most of the students were found with their drinking water pots from home.

This study has a few limitations. First, the data was a crosssectional; therefore, precise causes of micronutrient deficiencies could not be ascertained. Secondly, laboratory investigations were not carried out for blood for hemoglobin, MCV, hemoglobinopathies, stool examination etc. which would help exact diagnosis of some of the diseases.

\section{Conclusion}

The present nutritional health analysis study showed various signs of deficiencies and ill health among primary school children of North Kolkata. Anemia, worm infestations, vitamin B complex deficiencies and under-nutrition were common health problems found among them. Nutrition knowledge and effective school health programs should be implemented to address those health-related problems. Mass de-worming would also essential to address some of those deficiencies. Regular anthropometric measurements should be taken in the schools so that a regular watch can be kept on the growth and development of the children. The need of today is to keep children free from all diseases and provide them a healthy and hygienic environment, so that this future generation of the country can grow healthy and disease free.

\section{References}

1. Ong SG, Liu J, Wong CM, Lam TH, Tam AYC, Daniel $\mathrm{L}$ et al. Studies on the respiratory health of primary school children in urban communities of Hong Kong. Sci. Total Environ 1991;106:121-35.

2. Berger IB, Salehe O. Health Status of Primary School Children in Central Tanzania. J Trop Pediatr 1986;32:26-9.

3. Shakya SR, Bhandary S, Pokharel PK. Nutritional status and morbidity pattern among governmental primary school children in the Eastern Nepal. Kathmandu Univ Med J2004;2:307-14.

4. Chopdar A, Mishra PK. Health status of rural school children in Western Orissa. Indian $J$ Pediatr 1980;47:203-6.

5. Gupta BS, Jain TP. A comparative study of the health status of rural and urban primary school children. Indian JPediatr 1973;40:135-41.

6. Gupta RK, Bhat A, Khajuria RK, Bhat AM. Health status of primary school children in Jammu. Indian $J$ Prev Soc Med 1997;28:90-4.

7. Wandera M, Twa-Twa J. Baseline survey of oral health of primary and secondary school pupils in Uganda. Afr Health Sci 2003;3:19-2.

8. Ng'ang'a PM, Valderhaug J. Oral hygiene practices and periodontal health in primary school children in Nairobi, Kenya. Acta Odontologica Scandinavia 1991;49:303-9.

9. Al-Haddad AM, Bin Ghouth AS, Hassan HS, Distribution of dental caries among primary school children in Al-Mukalla area, Yemen. $J$ Dent 2006;3:195-8.

10. Mohammad K, Mohammadreza G, Isa Mohammdi Z. Prevalence of Refractive Errors in Primary School Children [7-15 Years] of Qazvin City. Eur J Sci Research 2009;28:174-85.

11. Lanz G, Zambrino CA, Termine C, Palestra M, Ferrari Ginevra O, Orcesi S et al. Prevalence of tic disorders among primary school students in the city of Pavia, Italy. Arch Dis child 2004;89: 45-7.

12. Uncu Y, Irgil E, Karadag M. Smoking Patterns among Primary School Students in Turkey. Scientific World J 2006; 6:1667-73.

13. AlBashtawy M, Hasna F. Pediculosis capitis among primary-school children in Mafraq Governorate, Jordan. East. Mediterr. Health J.2012; 18:43-8.

14. Central Pollution Control Board. Study on ambient air quality, respiratory symptoms and lung function of children in Delhi. Central Pollution Control Board, Ministry of Environment and Forests, India, 2008.

15. Waterlow JC, Buzina R, Keller W, Lane JM, Nichaman 
MZ, Tanner JM. The presentation and use of height and weight data for comparing the nutritional status of groups of children under the age of 10 years. Bull World Health Organ 1977;55:489-98.

16. Nutrition Sub-committee of the Indian Academy of Paediatrics. Classification of Protein Energy Malnutrition. Indian Pediatr 1972;9:360-41.

17. Sebastian CS. Pediatric mental retardation. http://emedicine.medscape.com/article/289117overview (accessed March 2012)

18 Agrawal M, Ghildiyal R, Khopkar S. Health Status of School Girls from Affluent Population of Mumbai. Indian Pediatr 1999; 36:75-8.

19. Basu M, Das P, Pal R, Kar S, Desai VK, Kaviswar A. Spectrum of visual impairment among urban female school students of Surat. Indian $J$ Ophthalmol 2011;59:475-9.
20. Das A, Dutta H, Bhaduri G, Dey Sarkar A, Sarkar K, Banerjee M. A study on refractive errors among school children in Kolkata. J Indian Med Assoc 2007; 105:16972.

21. Arkay A, Kara CO, Dagdeviren E, Zencir M. Variation in Tonsil Size in 4-to17-year School children. $J$ Otolaryngol 2006;35:270-4.

22. Bose K, Bisai S, Chakraborty J, Datta N, Banerjee P. Extreme level of underweight and stunting among preadolescent of lower socio-economic class from Madhyamgram and Barasat, West Bengal, India. Coll. Anthropol 2008;32:73-7.

24. International Institute of Population Sciences. National Family Health Survey (NFHS III) 2005-2006. Mumbai: International Institute of Population Sciences, 2005. 